Marc J. Struelens

\title{
Detection of microbial DNAemia: does it matter for sepsis management?
}

Received: 30 September 2009

Accepted: 17 October 2009

Published online: 19 November 2009

(C) Copyright jointly hold by Springer and ESICM 2009

This editorial refers to the article available at: doi:10.1007/s00134-009-1705-z.

M. J. Struelens $(\bowtie)$

Department of Microbiology, Université Libre de Bruxelles, Hopital Erasme, 808, route de Lennik, 1070 Bruxelles, Belgium e-mail: marc.struelens@ulb.ac.be

Sepsis is a major cause of morbidity and premature death. In the USA, severe sepsis has been shown to cause over 200,000 deaths per year [1]. Early administration of active antimicrobial therapy is a predictor of favorable outcome in severe sepsis arising from bacteremia and pneumonia $[2,3]$. However, targeting the etiological agents of sepsis is a clinical challenge as the range of pathogens and their resistance to antibiotics vary over time and place [4]. While broad spectrum empirical antimicrobial therapy allows to initially treat a majority of likely pathogens, every effort should be made to rapidly identify the causative pathogens and narrow the spectrum of therapy to minimize the development of antibiotic resistance. Currently, microbiological testing in sepsis still relies on blood cultures, microscopic examination and culture of specimens from the suspected focus of infection [5]. By nature, microbiological culture is a slow process. Typically, culture-based procedures detect bacterial pathogens within $12-48 \mathrm{~h}$, but fastidious pathogens such as yeasts can take longer. By conventional methods, microbial identification and drug susceptibility profiles require a further testing time of 6-24 h after isolation. Faster identification of microbial pathogens is achievable by using mass-spectrometry [6]. False-negative results do occur with blood cultures because of low microbial inoculum or growth inhibition by residual antibiotics in the sample. Therefore, faster and more sensitive diagnostic tests are needed to better target antibiotic therapy of bacterial and fungal infections and improve the management of patients with sepsis.

Multiplex analysis of nucleic acid sequences of microbial pathogens allows rapid detection and identification of pathogenic agents in clinical samples such as blood [5] or sputum [7]. Target genes include those of $16 \mathrm{~S}$ or $23 \mathrm{~S}$ ribosomal RNA, or the intervening spacer region, which allow reliable discrimination between bacterial species [5]. Two technologies have been developed: (1) real-time PCR, in which amplified segments of DNA are being monitored quantitatively by fluorescent dyes or labeled hybridization probes and (2) DNA microarrays, in which labeled ribosomal RNA or genomic DNA is detected by hybridization with specific DNA probes spotted on a solid phase [7,8]. The first such assay to undergo clinical studies in adult critical care is the SeptiFast $^{\mathrm{TM}}$ test. This commercial real-time PCR assay detects 25 bacterial and fungal species or genera that account for $>90 \%$ of bloodstream pathogens [7]. Observational studies comparing its accuracy to blood culture have indicated a sensitivity ranging between 60 and $95 \%$ and specificity between 74 and $83 \%$ in hemato-oncology, emergency and critical care settings [9-12]. PCR took a reported median time of 7-18 h from sampling to result. In these studies, many febrile episodes were associated with pathogen DNAemia detected by PCR but not by blood culture. Many of these "false-positive" PCR results were deemed clinically significant, based on retrospective patient chart review or subsequent isolation of the pathogen from relevant clinical samples [9-12].

In this issue, Bloos and colleagues report their findings on the diagnostic value and biological significance of this PCR assay [13]. In a multicenter prospective cohort study, they compared PCR on blood samples to blood cultures in 
142 surgical ICU patients with severe sepsis, $54.5 \%$ of whom had microbiologically documented infection. The same tests were performed in a control group of 63 postoperative patients without signs of infection. Secondary endpoints included organ dysfunction scores, biological markers of systemic inflammation and ICU mortality. Whereas control patients only showed $4.5 \%$ PCR and $3.6 \%$ blood culture with positive results, septic patients displayed $34.7 \%$ positive PCR tests and $16.5 \%$ positive blood cultures. PCR showed $70.3 \%$ pathogen detection sensitivity versus blood culture. PCR positive episodes were microbiologically confirmed from the site of infection with similar frequency (38\%) as blood culture positive episodes $(42 \%)$. Importantly, PCR positive episodes were associated with a more severe disease as indicated by significantly greater SOFA scores and increased interleukin-6 levels, even in patients with negative blood cultures. No significant prognostic impact was noted. The authors conclude that PCR-based pathogen DNA detection is biologically meaningful and clinically relevant in severely septic patients even in the absence of cultivable bacteria or fungi in blood, warranting investigation of its usefulness to guide antimicrobial therapy.

These new data confirm the moderate concordance between multiplex PCR and blood cultures and provide further evidence for the potential clinical relevance of microbial DNA detection. The strengths of the study are its prospective design, large cohort of severely ill patients and objective clinical and biological endpoints. What are the study limitations? Firstly, as acknowledged by the authors, the conclusion that PCR has a low rate of false positives in the absence of infection should be interpreted with caution as patients in the control group were not comparable to the septic group in terms of underlying disease, severity of illness and duration of ICU stay. Whether non-infectious processes may trigger microbial DNA translocation and positive PCR tests in patients with a longer stay in the ICU remains unclear. Second, inflammatory biomarkers were not systematically measured but at the discretion of the treating physicians, thus introducing the possibility of ascertainment bias. Third, appropriateness of empirical therapy was not assessed to allow estimation of potential improvement based on PCR results, as discussed by the authors.
What do these data add to our knowledge? The impacts of detectable bacterial and fungal DNAemia on the severity of sepsis and magnitude of inflammatory response are important observations pointing to its role in the pathophysiology of sepsis. The presence of toll-like receptors that recognize microbial nucleic acids on host cells mediating the innate immune response to pathogens makes this observation plausible. Further investigation should clarify the dynamics of pathogen DNA release and clearance in septic patients and its prognostic significance. The frequent discrepancy between detection of pathogen DNAemia and isolation by culture can be explained by several factors. DNA may be released in the bloodstream not only in viable pathogens, but also from dead microbial cells within phagocytes or by translocation of extracellular DNA from infected or colonized tissues. Likewise, antibiotic treatment may interfere with culture by killing or inhibiting the growth of infecting pathogens. Surprisingly, the present study reported a similar proportion of antibiotic-treated patients among those with negative PCRs or blood cultures. Conversely, bacteremia may be missed by PCR due to lower sample volume or a pathogen not in the test panel.

What are the practical implications of these findings? Before this or similar broad-range PCR assays can be incorporated into sepsis management algorithms, clinical benefit should be demonstrated by adequately powered controlled intervention trials. Given its sensitivity and time to results, it does not appear possible to use PCR to rule out infection or target antimicrobial therapy in patients suspected of sepsis. Future trials should test if PCR can effectively guide adjustment of therapy to detected pathogens and thereby improve the appropriateness of therapy for documented infection, reduce the total use of antibiotics and length of stay in the ICU, and possibly improve clinical outcome. In parallel, DNA detection technology should be further improved to include more pathogens and drug resistance determinants, increase the volume of blood analyzed, adapt to other clinical samples, provide results within $1 \mathrm{~h}$ and automate for random access, low skill laboratory or point of care testing. In other words, both technology development and clinical assessment should be actively pursued.

\section{References}

1. Angus DC, Linde-Zwirble WT, Lidicker J, Clermont G, Carcillo J, Pinsky MR (2001) Epidemiology of severe sepsis in the United States: analysis of incidence, outcome, and associated costs of care. Crit Care Med 29:1303-1310
2. Fraser A, Paul M, Almanasreh N, Tacconelli E, Frank U, Cauda R, Borok $\mathrm{S}$, Cohen M, Andreassen S, Nielsen AD, Leibovici L, TREAT Study Group (2006) Benefit of appropriate empirical antibiotic treatment: thirty-day mortality and duration of hospital stay. Am J Med 119:970-976
3. Bochud PY, Bonten M, Marchetti O, Calandra T (2004) Antimicrobial therapy for patients with severe sepsis and septic shock: an evidence-based review. Crit Care Med 32(Suppl 11):S495-S512 
4. Rello J, Sa-Borges M, Correa H, Leal SR, Baraibar J (1999) Variations in etiology of ventilator-associated pneumonia across four treatment sites: implications for antimicrobial prescribing practices. Am J Respir Crit Care Med 160:608-613

5. Dark PM, Dean P, Warhurst G (2009) Bench-to-bedside review: the promise of rapid infection diagnosis during sepsis using polymerase chain reactionbased pathogen detection. Crit Care 13:217

6. Seng P, Drancourt M, Gouriet F, La Scola B, Fournier PE, Rolain JM, Raoult D (2009) Ongoing revolution in bacteriology: routine identification of bacteria by matrix-assisted laser desorption ionization time-of-flight mass spectrometry. Clin Infect Dis 49:543-551

7. Francois $\mathrm{P}$, Charbonnier $\mathrm{Y}$, Jacquet $\mathrm{J}$, Utinger D, Bento M, Lew D, Kresbach GM, Ehrat M, Schlegel W, Schrenzel J (2006) Rapid bacterial identification using evanescent-waveguide oligonucleotide microarray classification. J Microbiol Methods 65:390-403
8. Burteau S, Bogaerts P, de Mendonça R, Irenge L, Berhin C, Hiffe J, de San N, Beyne P, Hamels S, Glupczynski Y, Struelens M, Gala JL, Remacle J (2008) Design and validation of a low density array (Nosochip) for the detection and identification of the main pathogenic bacteria and fungi responsible for nosocomial pneumonia. Eur J Clin Microbiol Infect Dis 27:17-27

9. Mancini N, Clerici D, Diotti R, Perotti M, Ghidoli N, De Marco D, Pizzorno B, Emrich T, Burioni R, Ciceri F,

Clementi M (2008) Molecular diagnosis of sepsis in neutropenic patients with haematological malignancies. J Med Microbiol 57:601-604

10. Louie RF, Tang Z, Albertson TE, Cohen S, Tran NK, Kost GJ (2008) Multiplex polymerase chain reaction detection enhancement of bacteremia and fungemia. Crit Care Med 36:14871492
11. Dierkes C, Ehrenstein B, Siebig S, Linde HJ, Reischl U, Salzberger B (2009) Clinical impact of a commercially available multiplex PCR system for rapid detection of pathogens in patients with presumed sepsis. BMC Infect Dis 9:126

12. Westh H, Lisby G, Breysse F, Böddinghaus B, Chomarat M, Gant V, Goglio A, Raglio A, Schuster H, Stuber F, Wissing H, Hoeft A (2009) Multiplex real-time PCR and blood culture for identification of bloodstream pathogens in patients with suspected sepsis. Clin Microbiol Infect 15:544-551

13. Bloos F, Hinder F, Becker K, Sachse S, Mekonto-Dessap A, Straube E, Cattoir V, Brun-Buisson C, Reinhart K, Peters G, Bauer M (2009) A multicentre trial to compare blood culture with polymerase chain reaction in severe human sepsis. Intensive Care Med. doi: 10.1007/s00134-009-1705-z 